\title{
Peripheral nerve surgery: the road less traveled
}

\author{
Lukas Rasulić $^{1,2}$
}

Received: 11 May 2018 / Accepted: 16 May 2018 / Published online: 23 May 2018

(C) Springer-Verlag GmbH Austria, part of Springer Nature 2018

\section{I shall be telling this with a sigh \\ Somewhere ages and ages hence: \\ Two roads diverged in a wood, and I- \\ I took the one less traveled by, \\ And that has made all the difference. \\ Robert Frost}

Although peripheral nerve surgery has always been an integral part of neurosurgery, its status within the global landscape of the field has long been in the shadow of the more prominent areas, such as skull base or vascular neurosurgery. The reasons are many, one of them plausibly being the conceptual frame of the very word "peripheral", which evoke the notions of marginality and lesser importance. Some of the related common misconceptions are that neurological deficit in peripheral nerve injury is permanent and irreversible, that peripheral nerves do not have the ability to regenerate, that the results of surgical treatment are insignificant, and that peripheral nerve surgery is not attractive for neurosurgeons but is rather reserved for plastic surgeons and orthopedics. Thanks to the dedicated work of a relatively small but enormously committed group of neurosurgeons across the world over the past decades; these fallacies have been dispelled, and it is becoming increasingly clear that peripheral nerve surgery is not peripheral in the above sense and that it deserves no less attention than its more prominent cousins.

Namely, although peripheral nerve surgery is not a lifesaving surgery, it has been proved to be a life-changing surgery, with a major impact on the quality of patient's life, as it improves the patient's ability to perform everyday and professional activities and thus affects his/her physical and

Lukas Rasulić

lukas.rasulic@gmail.com

School of Medicine, University of Belgrade, Belgrade, Serbia

2 Department of Peripheral Nerve Surgery, Functional Neurosurgery and Pain Management Surgery, Clinic for Neurosurgery, Clinical Center of Serbia, Belgrade, Serbia psychological well-being [9-11]. Moreover, since most patients with peripheral nerve injuries and brachial plexus injuries belong to the working-age population, peripheral nerve surgery also has substantial socioeconomic implications $[8,9]$. Contrary to the previously held view, the peripheral nerve system has been shown to have a huge regeneration potential, with significant results enhanced by different modalities of stimulation $[5,6]$, whereby recent research on brain plasticity indicates that experience-dependent reorganization of neural networks plays an important role in functional recovery $[3,4,13,14]$. For all these reasons, systematic research, education, and practice in peripheral nerve surgery is definitely worth the effort.

Dating back to the seventeenth century, when the first reconstruction of a transected nerve was performed by Ferrara in 1608 [1], modern peripheral nerve surgery started in the second half of the twentieth century, with the first use of operative microscope by Kurze in 1964 [15]. Since then, peripheral nerve surgery has come a long way, not only due the progress of science and technology which improved possibilities for the surgical treatment of peripheral nerve injuries, but alsoand more importantly - due to the long-lasting commitment of individual neurosurgeons from different institutions and countries worldwide, including in particular the following prominent names in the field of brachial plexus surgery: Sydney Sunderland, Hanno Millesi, Madjid Samii, Alain Gilbert, Algimantas Narakas, David Kline, Robert Spinner, Daniel Kim, Jamie Bertelli, and Mariano Socolovsky (and the list is not exhaustive) [2].

Within this global development, I would like to emphasize the groundbreaking contribution to the field by two Serbian neurosurgeons-Zoran Roganović, who published the largest series of war traumatic injuries of peripheral nerves after World War Two (including 139 brachial plexus injuries, resulting in 15 painful syndromes) $[10,11]$, and Miroslav Samardžić, the founding father of modern peripheral nerve surgery at the Clinic of Neurosurgery, Clinical Center of Serbia, where cca 3300 microsurgical reconstructions of peripheral nerves have been performed since 1980 
(including cca 2800 peripheral nerve lesions and cca 500 brachial plexus lesions) [12]. Their expertise and devotion have been invaluable in the shaping of the Belgrade school of peripheral nerve surgery, which has meanwhile received significant visibility on the world map of neurosurgery, and which I now represent, with a sense of pride and responsibility, in my capacity as Vice President of the WFNS Peripheral Nerve Surgery Committee and Chairman of the EANS Peripheral Nerve Section.

Until only recently, EANS was the only continental neurosurgical society without a separate section for peripheral nerve surgery. I would like to use this opportunity to thank the EANS Board for supporting my initiative to constitute the EANS Section for Peripheral Nerve Surgery and for placing their confidence in my appointment as its chairman - this decision was reached at the EANS Board meeting in Gava, Spain, in December 2016, and finally approved at the EANS General Assembly in Venice in October 2017. The EANS Section for Peripheral Nerve Surgery was established with the following goals: (i) improving knowledge and education in the field of PNS among young generations; (ii) enabling fellowships and internships (from 3 to 12 months) for young neurosurgeons who want to specialize in PNS, by establishing cooperation between European and World centers of excellence in the field; (iii) promoting multidisciplinary collaboration; (iv) raising global awareness about the importance of PNS; (v) identifying the needs of developing countries and providing professional support; (vi) establishing unified standards with regard to the level of neurosurgical technologies, which will be achievable and applicable in all countries, regardless of their current state; (vii) improving the quality of life and social impact; and finally, (ix) establishing a new surgical subspecialization in the future, named nerve surgeon. So far, 30 members from 11 countries have confirmed their interest to take active participation in the activities of the Section. Dr. Mariano Socolovsky, from Argentina, Chairman of the WFNS PNS Committee, has been elected honorary member of the Section, for his continuing endeavors in the international promotion and advancement of peripheral nerve surgery. The first business meeting of the EANS PNS Section was held in Belgrade, Serbia, in November 2017.

At the beginning of 2018, we conducted a survey among the EANS PNS Section members with the aim of determining the representation of peripheral nerve surgery in individual centers and countries of the Section members. The results obtained from Germany, the Netherlands, Denmark, Austria, Italy, Spain, Czech Republic, Serbia, and Albania show that, overall: (i) in terms of the number of neurosurgeons doing peripheral nerve surgery in relation to the total number of neurosurgeons across different centers in these countries, the average PNS representation amounts to approximately $25 \%$ of neurosurgeons doing peripheral nerve surgery, with significant variations across countries; (ii) in terms of the annual number of peripheral nerve surgeries across different centers in these countries, the most common surgeries are related to injuries and entrapments, while tumor, brachial plexus, and iatrogenic injuries are less represented (on average, approximately twice less than those in the former category); and (iii) there is a notable under-representation of endoscopic PNS repair, which is only done in rare centers in some countries (specifically, Germany, Denmark, Austria, Spain, and Czech Republic). These data indicate the need to increase neurosurgeons' attention to this field and to articulate future directions for the development of peripheral nerve surgery.

Encouragingly, recent years have seen a remarkable advancement in terms of the academic recognition of peripheral nerve surgery within the global landscape of neurosurgery. This development is evident in the number of PNS-related articles in the most eminent international neurosurgical journals, which has increased significantly over the past decade. Especially significant landmarks in this respect include: (i) the theme session Controversies in Peripheral Nerve Surgery at the 15th Interim Meeting of the World Federation of Neurosurgeons and the pertinent thematic supplement of the World Neurosurgery journal [7]; (ii) the international publication entitled Manual of Peripheral Nerve Surgery: From the Basics to Complex Procedures, edited by M. Socolovsky, L. Rasulić, R. Midha and D. Garozzo (Thieme, 2017); and, in particular, (iii) the current issue of Acta Neurochirurgica. The fact that EANS PNS Section has established cooperation with Acta Neurochirurgica as its affiliated journal is much appreciated, as it provides an important fruitful platform for further advancement in the field.

This promising progress obliges us to persevere and think ahead, to the benefit of our patients and the future generations of neurosurgeons. New horizons in the field of peripheral nerve surgery, including brachial plexus surgery, are yet to be reached. The future development will inevitably involve the application of non-suture techniques of nerve anastomosis and neurotubules, the pharmacological activation and stimulation of nerve regeneration, the expansion of knowledge of neurotropism and neurotrophism, a better understanding of the concept of cell neurosurgery, and further research regarding brain plasticity. A multidisciplinary approach is mandatory, involving genuine collaboration of neurosurgeons, vascular surgeons, plastic surgeons, orthopedics, neurologists, radiologists, physiatricians, psychologists, and psychiatrists. Thereby, one thing remains constant as an irreplaceable factor regardless of what the world will look like in the future - it is the expertise and the hand of the surgeon.

With this in mind, I would like to draw your attention to the following academic and educational events aimed at enhancing the quality of peripheral nerve surgery in the twenty-first 
century: Copenhagen Peripheral Nerve Surgery Course 2018, $3 r d$ WFNS Theoretical \& Practical International Course in Peripheral Nerve \& Brachial Plexus Surgery in Frankfurt in 2018, and Peripheral Nerve Surgery Session at EANS Congress in Brussels in 2018; and there are many more planned for 2018-2020, such as German Nerve Club; Peripheral Nerve Surgery Course, Gunzburg/Ulm, Germany; Leiden Nerve Courses, and many more.

Finally, let me conclude on a personal note. After nearly three decades of experience in peripheral nerve surgery at the Clinic for Neurosurgery at the Clinical Center of Serbia- the experience shaped in unfavorable material conditions, through both civil and, sadly, war practice, including a period of international isolation, but always guided by exemplary expertise - I am happy to say that, if I were to start anew, I would go for peripheral nerve surgery again. It is a complex and demanding but exciting and rewarding area, which opens new perspectives in the understanding of neurosurgical treatment. I am confident that taking this less traveled road can bring important new advances in the wide world of neurosurgery, surgery, and medicine in general.

\section{References}

1. Artico M, Cervoni L, Nucci F, Giuffre R (1996) Birthday of peripheral nervous system surgery: the contribution of Gabriele Ferrara (1543-1627). Neurosurgery 39:380-382 discussion 382-383

2. Friedman $\mathrm{AH}$ (2009) An eclectic review of the history of peripheral nerve surgery. Neurosurgery 65:A3-A8. https://doi.org/10.1227/ 01.NEU.0000346252.53722.D3

3. Malessy MJ, Thomeer RT, van Dijk JG (1998) Changing central nervous system control following intercostal nerve transfer. J Neurosurg 89:568-574. https://doi.org/10.3171/jns.1998.89.4.0568

4. Malessy MJ, van der Kamp W, Thomeer RT, van Dijk JG (1998) Cortical excitability of the biceps muscle after intercostal-tomusculocutaneous nerve transfer. Neurosurgery 42:787-794; discussion 794-785
5. Mashhoudi Barez M, Tajziehchi M, Heidari MH, Bushehri A, Moayer F, Mansouri N, Safavi Naini N, Movafagh A (2017) Stimulation effect of low level laser therapy on sciatic nerve regeneration in rat. J Lasers Med Sci 8:S32-S37. https://doi.org/10. 15171/jlms.2017.s7

6. Nicolas N, Kobaiter-Maarrawi S, Georges S, Abadjian G, Maarrawi $\mathrm{J}$ (2018) Motor cortex stimulation regenerative effects in peripheral nerve injury: an experimental rat model. World Neurosurg. https:// doi.org/10.1016/j.wneu.2018.03.090

7. Rasulic L (2015) Introduction: facing the challenges of peripheral nerve surgery in the 21st century. World Neurosurg 84:596. https:// doi.org/10.1016/j.wneu.2015.05.054

8. Rasulic L, Puzovic V, Rotim K, Jovanovic M, Samardzic M, Zivkovic B, Savic A (2015) The epidemiology of forearm nerve injuries - a retrospective study. Acta Clin Croat 54:19-24

9. Rasulic L, Savic A, Zivkovic B, Vitosevic F, Micovic M, Bascarevic V, Puzovic V, Novakovic N, Lepic M, Samardzic M, Mandic-Rajcevic S (2017) Outcome after brachial plexus injury surgery and impact on quality of life. Acta Neurochir 159:12571264. https://doi.org/10.1007/s00701-017-3205-1

10. Roganovic Z, Mandic-Gajic G (2006) Pain syndromes after missilecaused peripheral nerve lesions: part 1 - clinical characteristics. Neurosurgery 59:1226-1236; discussion 1236-1227. https://doi. org/10.1227/01.NEU.0000245610.01732.32

11. Roganovic Z, Mandic-Gajic G (2006) Pain syndromes after missilecaused peripheral nerve lesions: part 2-treatment. Neurosurgery 59:1238-1249; discussion 1249-1251. https://doi.org/10.1227/01. NEU.0000245618.16979.32

12. Samardzic M, Rasulic LG, Grujicic DM, Bacetic DT, Milicic BR (2011) Nerve transfers using collateral branches of the brachial plexus as donors in patients with upper palsy - thirty years' experience. Acta Neurochir 153:2009-2019; discussion 2019. doi: https://doi.org/10.1007/s00701-011-1108-0

13. Socolovsky M, Malessy M, Lopez D, Guedes F, Flores L (2017) Current concepts in plasticity and nerve transfers: relationship between surgical techniques and outcomes. Neurosurg Focus 42:E13. https://doi.org/10.3171/2016.12.FOCUS16431

14. Taylor KS, Anastakis DJ, Davis KD (2009) Cutting your nerve changes your brain. Brain 132:3122-3133. https://doi.org/10. 1093/brain/awp231

15. Uluc K, Kujoth GC, Baskaya MK (2009) Operating microscopes: past, present, and future. Neurosurg Focus 27:E4. https://doi.org/ 10.3171/2009.6.FOCUS09120 